Presented at the Particle Accelerator Conference, Chicago, IL., March 1971
UCRL-20191

Preprint

CoNf $710308--8$

\title{
NEW BEVATRON POLE-FACE WINDINGS POWER SYSTEM
}

L. T. Jackson

February 1971

AEC Contract No. W $-7405-$ eng -48

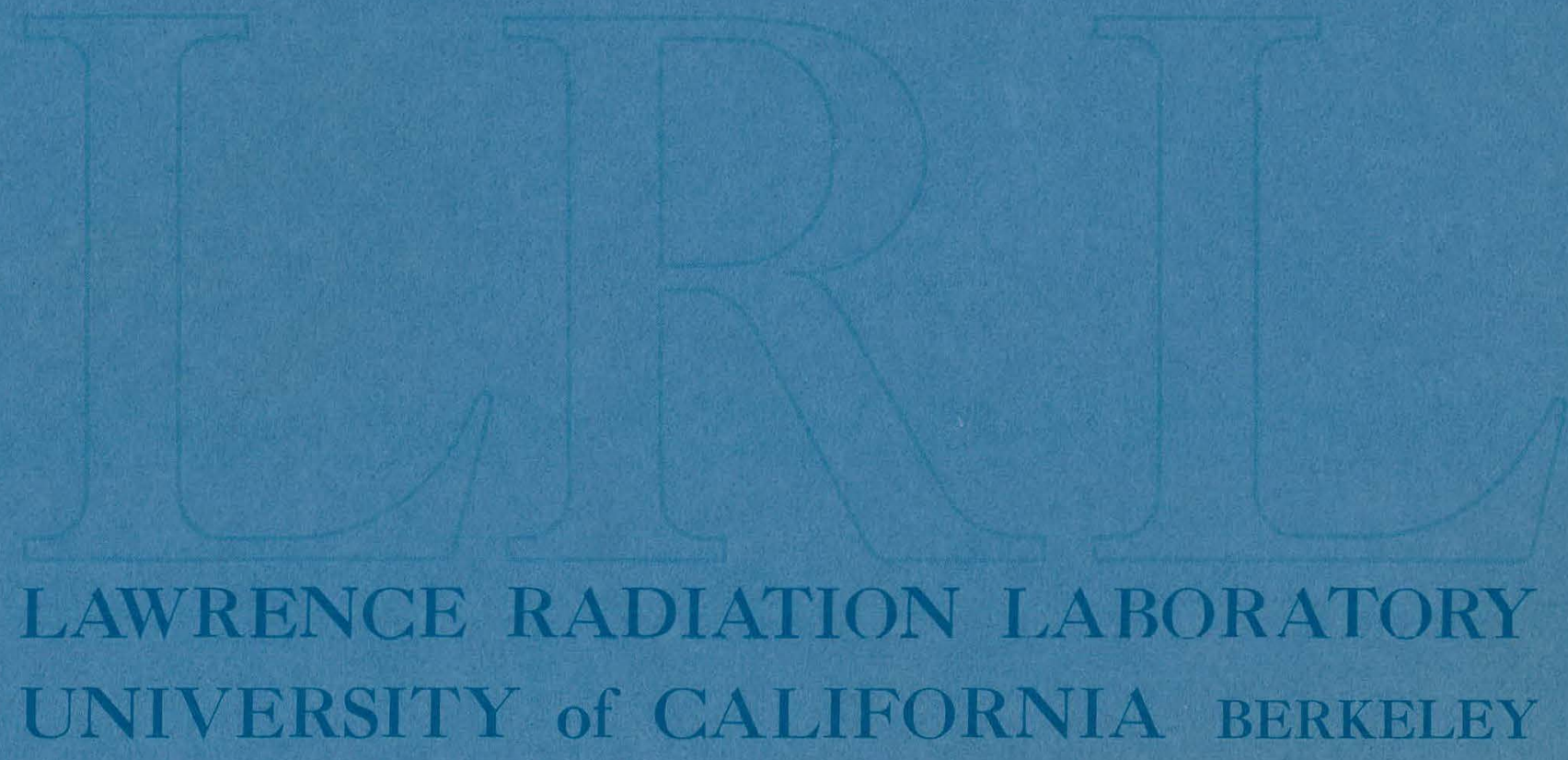




\section{DISCLAIMER}

This report was prepared as an account of work sponsored by an agency of the United States Government. Neither the United States Government nor any agency Thereof, nor any of their employees, makes any warranty, express or implied, or assumes any legal liability or responsibility for the accuracy, completeness, or usefulness of any information, apparatus, product, or process disclosed, or represents that its use would not infringe privately owned rights. Reference herein to any specific commercial product, process, or service by trade name, trademark, manufacturer, or otherwise does not necessarily constitute or imply its endorsement, recommendation, or favoring by the United States Government or any agency thereof. The views and opinions of authors expressed herein do not necessarily state or reflect those of the United States Government or any agency thereof. 


\section{DISCLAIMER}

Portions of this document may be illegible in electronic image products. Images are produced from the best available original document. 
NEW BEVATRON POLE-FACE WINDINGS POWER SYSTEM*

\author{
L. T. Jackson
}

Lawrence Radiation Laboratory, University of California Berkeley, California

\section{Introduction}

The new power systems which individually drive each of the Bevatron pole-face windings must handle a variety of operating parameters as well as satisfying the stringent specification of $d I / d t \leq 14 \mathrm{~A} / \mathrm{sec}$ during flattop. The 19 pole-face windings, which run circumferencially around the machine, each constitutes an active load for their power system, with $B$ voltages increasing with radius up to $190 \mathrm{~V}$ during rectification on the outermost winding. During flattop there is approximately $10 \mathrm{~V}$ pp of predominately 720 and $1440 \mathrm{~Hz}$ signals across the winding. The $0.5 \Omega$ windings require up to $+30 \mathrm{~A}$ during injection and $\pm 100 \mathrm{~A}$ during flattop.

To satisfy the above requirements, a transistor actuator was chosen utilizing 2 N 3902 high-voltage transistors. A dc supply with multiple taps on the transformer provides output voltages from $12 \mathrm{~V}$ to $270 \mathrm{~V}$ to allow matching to each pole-face winding with a voltage higher than the $B$ voltage of that winding so the difference appearing across the actuator is correct for transistor operation. On the positive actuator, the difference voltage must be great enough to drive the $30 \mathrm{~A}$ peak required through the winding during injection. Characteristic waveshapes for PFW13 positive and negative actuators are shown in Fig. 1.

\section{Equipment}

The 2 N3902 has a maximum power rating of $100 \mathrm{~W}$, but above $80 \mathrm{~V}$ is second breakdown limited. It was necessary to add $0.25 \Omega$ resistors in series with windings 11,12 , and 13 to keep the load line within the transistor's safe operating area with $\mathrm{B}+=115 \mathrm{~V}$. Pole-face windings 14,15 , and 16 require only negative current during flattop, so rather than install prohibitively large series resistors to keep within safe limits on positive currents due to the increased $\mathrm{B}+$, the computer terminal does an ExI product with an update time of Imsec. Upon sensing a beyond-limit power level the reference word at the computer terminal is zeroed and the supply contactor opened. The zeroing catches any non-allowed reference signals before harm can be done. The contactor clearing time of $32 \mathrm{msec}$ will prevent transistor failures for most of the other possible foult conditions.

Twenty-four output and one driver stage 2N3902's are mounted on each of the two water-cooled slabs in an actuator. The 2N3902's operate at 100W dissipation with no more than a $55^{\circ} \mathrm{C}$ case temperature. The actuator is photographed in Fig. 2, and the system schematic is shown in Fig. 3. The low-powered electronics on printedcircuit boards are nested in between the two water-cooled slabs. The three boards contain (1) the regulator and monitor amplifiers and the Digital-Analogue Converter, (2) the pre-drivers and current limiters, and (3) the pulse-curation-modulation receiver (serial data). The regulator and monitoring shunts are also mounted between the slabs on a copper bar connected to the back slab at the right side of Fig. 2. Each shunt is composed of two paralleled $0.02 \Omega 25 \mathrm{~W}$ Daleohm resistors arranged in a quasi-cosxial configuration with the incoming and outgoing cables. by leading in the cable between the two resistors and thereby having the return currents through the resistors above and below the cable, the frequency response is enhanced and pickup minimized. The close-proximity of all the active elements in the closed loop system also substantially reduces pickup and maximizes the frequency response.

* This work performed uncer the auspices of the Atomic Energy Commission.
The electronic power supplies and metering can be seen in an adjacent chassis to the left of the actuat or. All the connecting leads are buffered at the actuator.

Every attempt has been made to design a reliable system because the operation of the Bevatron is directly dependent on it. But in the event of malfunction, rapid replacement of any part of the system is requirsd. To facilitate maintenance, all the major and minor parts are completely interchangeable between each system. All the boards are interchangeable; the pre-driver boards made so by having both the + and - actuator predrivers mounted on all boards and then choosing the appropriate one by the cable connection. In the event that many of the output transistors are blown (each one individually disconnects by having $0.3 \Omega$ fuseable emitter resistors), the complete actuator can be quickly slid out by disconnecting three lugs, the electronic cables and two quick-disconnect water fittings.

\section{Operation}

Because of having an active voltage source in tha load, the actuators are driven in the common-emitter connection. This configuration stacks the common of + and - power supplies away from ground by the load voltage and gives the actuator voltages shown in Fig. 1. By minimizing the capacity to ground of the power supplies and having a transformer capacity of $0.01 \mu \mathrm{fd}$. $t$ le tank circuit formed by this effective $C$ and the $L=400 \mathrm{IH}$ of the windings is kept well beyond the active freque scy range of the closed-100p. The positive actuator then acts as a current source driving the pole-face windin? through the power supply. The effective collector resistance of the fifty $2 \times 3902$ 's at $1 \mathrm{~A}$ is $15 \Omega$, which appears in shunt with the idealized current source, a d with the $400 \mu \mathrm{H}$ load and determines the transfer respo ise between the amplifier output voltage and the shunt voltage. The same actuator becomes the negative actuator by driving the PNP $2 N 5416$ pre-driver rather than the $2 N 3439$ for the positive side. The effective collector resistance for this side is $10 \Omega$ for the total actuator.

There are two transistor protection systems buil into the actuators. The first involves diode clamps across each actuator with related 10,500 f d capacitor banks across the power supplies. When an actuator is turned-off at the end of flattop, the current flowing in the load commutates from this actuater to the diod: across the other actuator through the associated capacitor bank. The energy transferred to the bank raises its voltage $5 \mathrm{~V}$; the $1500 \Omega$ across the capacitor; returns the voltage to normal before the next pulse. On positive-actuator-only systems, a IA supply, capacitor bank, and diode are used to provide the same function. The supply is adjusted to bias the capacitors to a high enough voltage that the diode isn't turned on during inversion.

The second protection system utilizes FET transistors (2N4391) as current limiters in the pre-drivers stages of the negative actuator. The 2 N5416's span the same voltage renge as the $2 \mathrm{~N} 3902^{\prime} \mathrm{s}$, and if a turnon signal cones along just after a turn-off and while the load is commuteting, the transistor would be overpowere $d$ without the current-limiting feature. The limiters are also flaced in the positive pre-drivers to limit the drain on the $+15 \mathrm{~V}$ supply.

\section{Performance}

The I specification placed on the current translates to $I_{p k}=6 \mathrm{~mA}$ at $360 \mathrm{~Hz}$ and proportionately lower 
at higher frequencies. The higher frequency components in the B voltage will be attenuated by the M.G. passive filter so the critical component is that at $360 \mathrm{~Hz}$. The $6 \mathrm{~mA}$ allowable appears at the shunt as $60 \mu \mathrm{V}$, so front-end amplifier noise must be low. The corner frequency of the system excluding the load is approximately $70 \mathrm{kHz}$. But because of the distributed nature of the pole-face windings, the first of many resonances occurs at $25 \mathrm{kHz}$ and therefore limits the loop-closing frequency to $10 \mathrm{kHz}$.
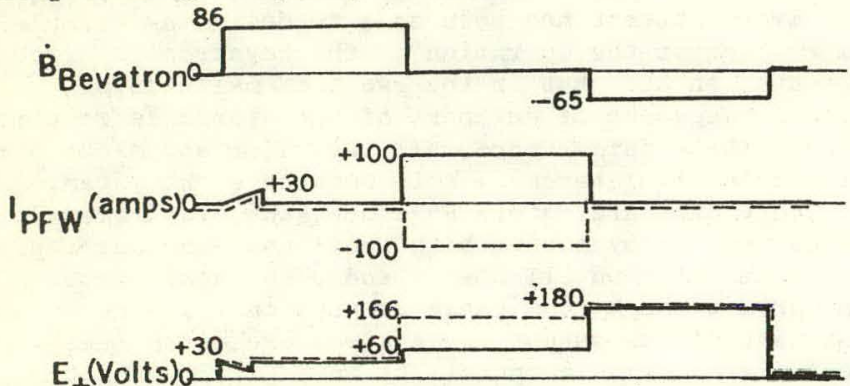

E_Voltso

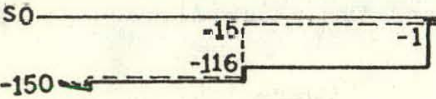

+current during flat top

$B+=116 \mathrm{~V}$

$B-=66 \mathrm{~V}$

Fig. 1 - Waveshapes of PFW 13 with max. currents.
A major concern in the stability analysis was the possible instability caused by the 19 pole-face winding systems, the ripple reduction system, and the motorgenerator system all being coupled together through the common magnet. The basic approach was to make the poleface systems single time-constant loops and rely on the poor coupling to the higher-order ripple-reduction system to minimize interraction. Two prototype systems have been operated on "nearest neighbor" windings with ripple reduction on and no degradation was discernable.

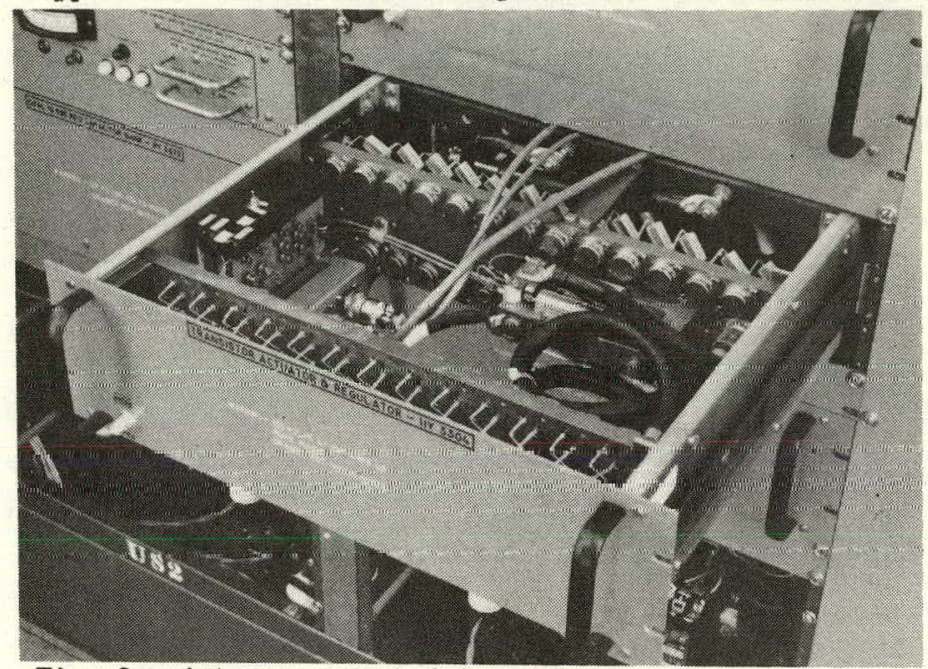

Fig. 2 - Actuator mounted in rack.

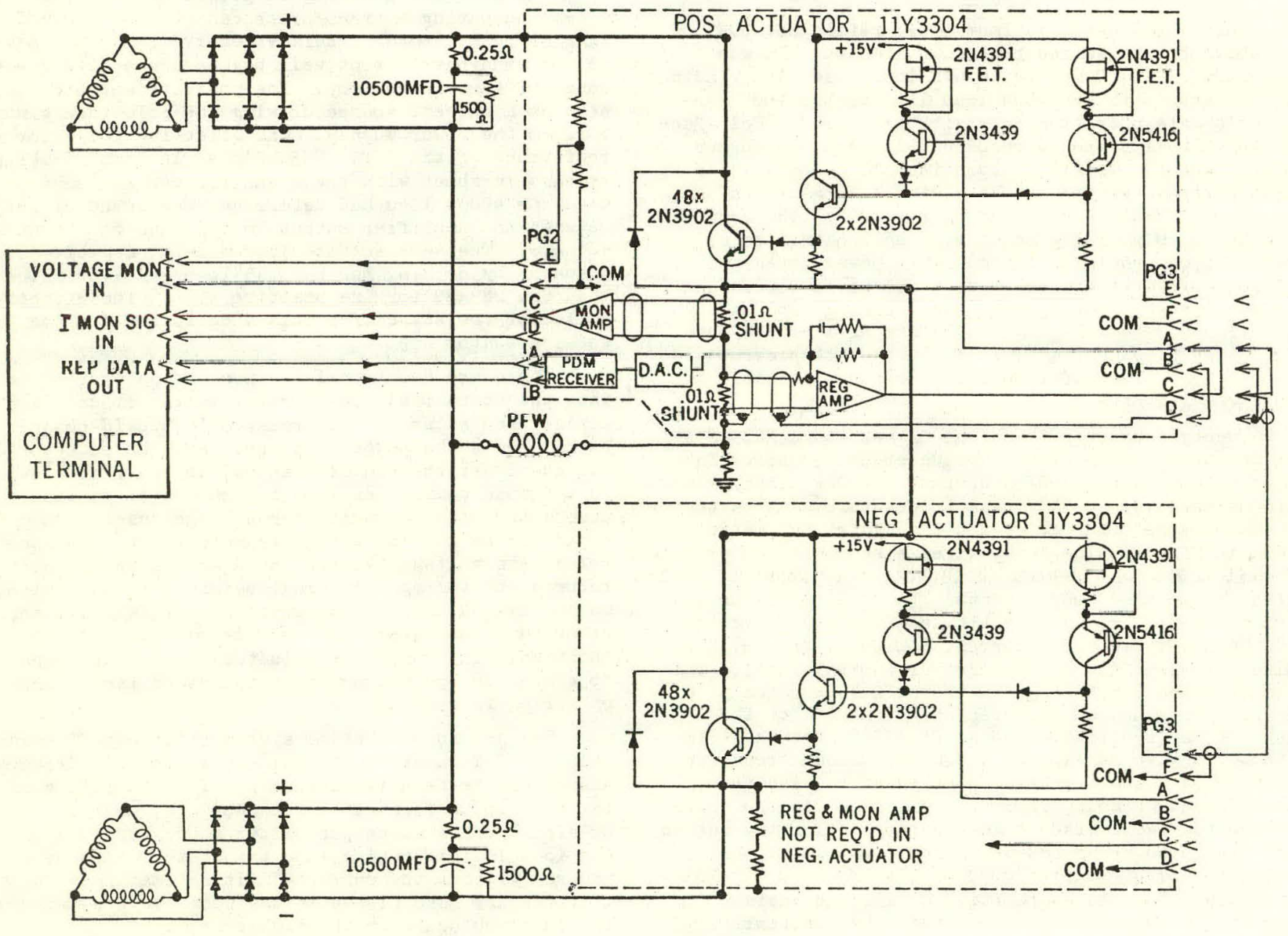

Fig. 3 - General diagram of Pole-Face Winding power system. 
This report was prepared as an account of work sponsored by the United States Government. Neither the United States nor the United States Atomic Energy Commission, nor any of their employees, nor any of their contractors, subcontractors, or their employees, makes any warranty, express or implied, or assumes any legal liability or responsibility for the accuracy, completeness or usefulness of any information, apparatus, product or process disclosed, or represents that its use would not infringe privately owned rights. 
TECHNICAL INFORMATION DIVISION

LAWRENCE RADIATION LABORATORY

UNIVERSITY OF CALIFORNIA

BERKELEY, CALIFORNIA 94720 